\title{
REFLEXÕES SOBRE O TRABALHO: “A RESILIÊNCIA E O MORAR NA RUA: ESTUDO COM MORADORES DE RUA CRIANÇA E ADULTOS - NA CIDADE DE SÃO PAULO”, DE APARECIDA MAGALI DE SOUZA ALVAREZ (1999)
}

\author{
REFLECTIONS ON THE ARTICLE: "RESILIENCE AND \\ HOMELESSNESS: A STUDY ON HOMELESS - ADULTS AND \\ CHILD - IN THE CITY OF SÃO PAULO”, BY \\ APARECIDA MAGALI DE SOUZA ALVAREZ ( 1999)
}

Sueli Damergian *

DAMERGIAN, S. Reflexões sobre o trabalho: “A resiliência e o morar na rua: estudo com moradores de rua - criança e adultos - na cidade de São Paulo”, de Aparecida Magali de Souza Alvarez (1999). Rev. Bras. Cresc. Desenv. Hum., 9(1), 1999.

\begin{abstract}
Resumo: Este artigo busca estabelecer um diálogo com o trabalho: “A resiliência e o morar na rua: estudo com moradores de rua- criança e adultos - na cidade de São Paulo”, através de reflexões suscitadas a partir do mesmo. A temática da resiliência e do morar na rua é relacionada ao modelo neoliberal vigente em nosso país e ao processo de exclusão social dele resultante. Algumas concepções sobre resiliência são discutidas para mostrar que ainda não existe consenso sobre o assunto. A vida dos moradores de rua é analisada a partir do interjogo entre os conceitos de identidade, insegurança ontológica, desconfirrnaçao existencial e ponto fixo enquanto alavanca para a resiliência: as interações amorosas como fundamento da existência e afirmação do eu.
\end{abstract}

Palavras-chave: exclusão social; interação amorosa; ponto fixo; identidade.

"Há alguém que revisite esse tempo de uma lentidão insidiosa durante o qual se transformou num daqueles que, embora vistos, embora ouvidos, não são olhados, não são escutados e que, aliás, se calam? Um daqueles que ninguém "considera”, nem reconhece, a não ser como fantasmas folclóricos, que não têm direito à carne das palavras, mas a siglas, a espectros de palavras: P. Mistas (rendaminirna); SMI Cards (salário minimo) ou, então ... nada” (FORRESTER, 1997).

E dos que apenas aparecem em números, estatísticas frias, siglas, como diz acima Viviane Forrester, que não se presentificam na materialidade da dor da existência humana, que tão bem trata o trabalho que aqui comentamos. E com que sincronicidade! Emerge no momento mais crítico deste fim de século, em que uma grande parte da população mundial e da população brasileira precisa mobilizar intensamente aspectos de sua pulsão de vida que lhes permita sobreviver, reunidos que estão sob a sigla dos excluídos.
Segundo O Mapa da Exclusão publicado pela Folha de São Paulo (1998) o Brasil possui: 63\% de excluídos (63,6 milhões de pessoas), dos quais 23\% (24 milhões de pessoas) são despossuídos; 24\% são miseráveis (25 milhões de pessoas) e 15\% são pobres (15 milhões de pessoas). Não são todos moradores de rua. Muitos possuem um teto, à semelhança de casa e apenas isso, como os flagelados da seca no Nordeste. Teimam em existir. À revelia do FMI, do capital especulativo, dos nossos narcisicos governantes - os maus pais sociais. Nunca a vaidade, a voracidade e a onipotência arrogante foram tão longe no seu trabalho de violentar a ética, os sentimentos, o humano.

Esses maus pais sociais representam a face tanática da sociedade, o "anti-ponto fixo” ou o ponto do nada, em que o povo não pode se apoiar, em contra-posição ao barraco do Hélio, porto seguro, reduto de Eros para aqueles que buscam um caminho que dê significado à vida.

Profa. Dra. do Departamento de Psicologia Social do Instituto de Psicologia da USP. 
A leitura deste trabalho nos leva obrigatoriamente a um paralelo entre os moradores de rua e a capacidade de resiliência de alguns deles e as perdas causadas a várias gerações de brasileiros pelo modelo neoliberal vigente em nosso país: idosos / aposentados / doentes que teimam em sobreviver, talvez para tristeza dos que nos governam; adultos sem presente implorando para trabalhar à porta das fábricas e lutando para não se entregarem ao nada; jovens e crianças sem escola, sem presente, sem futuro. Quem sabe, próximos candidatos as estatísticas sobre os moradores de rua.

É obrigatório, portanto, destacar a importância do trabalho de Magali apontando-nos para um problema que deve mobilizar as ações de Saúde Pública (ela existe?...) enquanto responsável pelo bem estar físico e mental dos cidadãos. Se os recursos são precários ou inexistem, há um que não depende de datações orçamentarias: o amor, as forças de vida, o desejo enquanto expressão da vontade, a solidariedade, a ética, a empatia. São valores que Magali nos mostra no cotidiano de seus moradores de rua em constante luta contra a indiferença, o ódio, as drogas, o álcool, a violência e que comentaremos a seguir.

\section{DO CONCEITO: RESILIÊNCIA}

É um conceito chave no trabalho e parece não estar ainda firmemente estabelecido entre seus autores. Algumas conceituações apresentadas mostram que falta consenso entre eles.

Assim, Broffenbrenner se refere à resiliência como uma qualidade que passava de uma geração à outra e estava associada à esperança quanto ao futuro possuída por pessoas submetidas ao sofrimento (pág. 23).

Rutter fala em resiliência como um conjunto de processos sociais e intra-psiquicos que ocorrem no tempo, dadas certas combinações benéficas de atributos da criança, familia, ambiente social e cultural. Resiliência, nesse sentido, envolve todos os processos psico-sociais que subjazem ao desenvolvimento saudável (pág 24).

Grotberg define a resiliência como a capacidade humana para fazer frente às adversidades da vida, superá-las e delas sair fortalecido ou transformado. Grotberg diz que a maioria das crianças não é resiliente e a maioria dos pais não as ajudam a adquirir resiliência (pág. 38).

Enquanto Grotberg fala da necessidade de adquirir resiliência, Rutter (pág. 24) afirma que a resiliência não pode ser vista como um atributo nascido com a criança ou adquirido em seu desenvolvimento. A autora optou por Grotberg em seu trabalho e através dele mostra que se a resiliência não é adquirida, é estimulada. Entretanto, há questões a resolver. Ela já existia ou não? É evidente que diz respeito à força de vida e se apoia no ponto fixo mas é necessário pesquisá-lo e clarifica-lo mais profundamente.

\section{DA OPÇÃO TEÓRICA}

A autora se apoia no pensamento de Morin, o que nos leva a enfatizar a importância de abrir o diálogo com o universo, que permite pensar com reticências, como costumamos dizer e não com pontos finais, abrindo mão das certezas e tomando-nos disponíveis para as verdades e imprevistos que a vida e o conhecimento constantemente nos trazem. O jogo do claro/escuro, que é a complexidademostradapor Morin, é a única fomma de se chegar ao humano, já que é impossível apreendê-lo em sua totalidade. É preciso destacar a coragem da autora para enfrentar o escuro, o desconhecido, sem simplificar, sem tentar enquadrar o humano em fórmulas reacionistas que esvaziam-no de sua essência, de seus afetos, de seus desejos.

O caminho seguido permite-nos ir em busca do ser humano total, da união entre a razão e emoção, de metáfora e metonímia. Permite-nos a superação da razão fechada, que é também racionalização (perversão da razão) e não racionalidade.

O modelo do complexos, que permite a compreensão da vida, nada mais é que a síntese de opostos que caracteriza o humano, segundo Kierkegaard: finito/infinito; temporal/eterno; necessidade/liberdade (1964). Alguns moradores de rua declaram que eles não são apenas necessidade, fome. Têm desejo, dignidade, exprimem o desejo de ser, a liberdade para existir, sem os constrangimentos a que são submetidos.

\section{DA PESQUISADORA E DO MÉTODO}

Tratamos aqui de aspectos indissociáveis em sua coerência quanto à construção do trabalho. Aliás, teoria, método, problema, enquanto escolhas, repetem a alma da pesquisadora. De certa forma, também é uma resiliente: emergiu plena, enriquecida através de seu trabalho realizado em condições bastante inóspitas de insegurança, perigos, dores. Quando fala de seu esquecimento que quase a levou a ser atropelada, aparece a sua capacidade de entrar no mundo do outro, uma entrega quase psicótica mas, fundamentalmente, uma revèrie, como diria Bion. Colocou-se como a mãe capaz de acolher as dores e sofrimentos, 
como um ponto fixo, por que não? É impossível não notar que ‘Cara Queimada’ se arruma, se enfeita, veste roupas novas por amor a ela, por ser aceito, por ser reconhecido como humano.

A sensação mágica de adentrar outra realidade através de uma porta virtual, como diz, pode ser feita sob a forma de êxtase: estético, religioso, artístico. A fusão de que fala Marion Milner (1969): capacidade do ego para tolerar uina perda momentânea de seus limites e se entregar à vivência de uma outra realidade, fundir-se com o cenário, abrindo mão de seus referenciais cotidianos.

E só assim que a porta mágica se abre e a pesquisa se torna humana, porque trata com seres humanos e não objetos e é preciso apreendê-los, coinpreendê-los e não apenas descrevê-los. Fala em “descontrair” o olhar. Diria que, ao despir-se dos preconceitos, dos pré-juízos, de seus estilos de vida para apreender o morador de rua, efetuou uma "redução eidética” em relação a tudo isto, à sua vida urbana normal, deixada entre parênteses temporariamente para poder abrir a porta mágica que leva ao mundo dos moradores de rua.

A coerência se faz presente nas análises dos depoimentos, nos destaques que faz e na hipótese que se confirma.

\section{DOS MORADORES DE RUA, SEU DISCURSO E SEU MUNDO: UM RETRATO EM PRETO (DOR), BRANCO, CINZA E A CORES (AMOR)}

É o retrato do mundo trazido pela pesquisadora que se materializa em seu trabalho.

Retrato da luta para ser, antes que para ter (e quando não se tem nada ...). É o emergir da questão básica da identidade, que se funda na alteridade e no seu duplo aspecto, psíquico e social: o desejo de reconhecimento e a necessidade de reconhecimento do desejo, como mostra Enriquez (1990).

Nos depoimentos dos moradores de rua vêm à tona problemas relativos à insegurança ontológica, à questão existencial, à perda de temporalidade (inexistência de futuro e ausência de sentido pessoal - sentimento de que a vida nada tem a oferecer que valha a pena). E eles nos levam a Giddens (1997), que nos mostra como esses aspectos se transformam em um problema psíquico fundamental nas circunstâncias da modernidade tardia. Os que conseguiram se recuperar ancoraram-se em um projeto, deram sentido a suas existências: Hélio e seu filho Lino (mostrando a reciprocidade dos pontos fixos); Neilton, Lino e Hélio, histórias de pontos que se entrelaçam, de apoios que se consolidam.
E Cara Queimada, mantendo-se sóbrio e assumindo o papel de Jamelão, transformando-se em um modelo positivo. É o afirmar que quer para os outros o melhor, porque a vida da rua não é vida.

E D. Silvia, o pessoal da sopa, âncoras e incentivos para busca de um sentido para a vida.

E o barraco do Hélio, abrigo generoso para os que queriam sair da rua, facilitando a busca de significado, a construção de um projeto existencial. Aparece aqui a solidariedade e a proximidade entre os pobres, traço comum entre as populações desfavorecidas. Hélio e sua generosidade natural para acolher estranhos e morar com não familiares, colocando a interdição necessária: não estar bêbado nem drogado como condição para o acesso ao barraco. É o amor no sentido mais amplo, Eros, que tudo une e constrói, a colorir a vida cinzenta dos excluídos.

O contraponto negro é representado pelo cotidiano da bebida, do entorpecimento, da anulação do sujeito pela ausência de perspectivas. E aparecem Célia e as drogas; Maria / Zé Roberto e o álcool, a violência, o medo, a morte.

O cotidiano dos moradores de rua se mostra como um mundo de paradoxos, como o outdoor que é retratado em uma das fotos: “A garantia de seu futuro”; “São Paulo, a capital mundial da gastronomia”; Mundo de antíteses, de vida (Lino) e morte (Jamelão); de amor e ódio; de generosidade e indiferença; de acolhimento e abandono; de pontos fixos e de nada.

O ódio aparece no discurso de Neilton, a sociedade planta o ódio e colhe o ódio: “... meu coração já tava ficando maldoso, porque eu já tava ficando com ódio da sociedade”. Mas o amor também aflora em seu discurso, através da figura dos pais, modelos saudáveis de identificação, em quem busca inspiração: "Eu ando de cabeça erguida mesmo! Eu acho isso lindo em mim! Aprendi com meu pai, digno mesmo!”

A falta de acolhimento, de modelos saudáveis é contada por 'Cara Queimada’ em suas histórias de abandonos: "Me acostumei aqui e me esqueci até da família; num é que esqueci; minha família também nunca ligaram para mim”.

O ponto fixo, modelo saudável está em Lino criança, em Neilton, que ajuda a cuidar do menino; o que o leva a reerguer-se, em Hélio, que consegue dar ao filho o que não teve da família maternagem e paternagem. O menino o estimulou a construir o barraco, a aumentá-lo, a ter um significado para existir. São pontos fixos que se entrelaçam, construindo vidas.

E o trabalho como ponto fixo, produzindo um vínculo com a realidade em Neilton: "O cara que venha dizer que sou isso, que sou aquilo... Não sou! Eu sou eu! Trabalhador!... 
E o problema da identidade em seu duplo aspecto, psíquico e social, através do desejo de reconhecimento e necessidade do reconhecimento do desejo. É Neilton afirmando: “eu não posso me identificar para você, que eu não tenho documento mas um dia eu vou mostrar pro senhor quem eu sou”. É a necessidade do outro, do olhar que confirma ou nega a existência.

O olhar que perpassa o corpo nômade devassa sua identidade exposta na rua. Giddens (1997) cita Goffman e sua teoria da indiferença civil: contrato implícito de reconhecimento mútuo que é feito pelos participantes nos cenários públicos da vida social. Segundo Goffman, quando duas pessoas se encontram na rua, demonstram pelo olhar que são dignas de respeito, que não se sentem ameaçadas.

Esses rituais efetuados em cenários públicos, para Goffman, são mais do que formas de proteger a auto-estima de cada um e dos outros, além de serem usados para atacar ou minar a auto-estima. Eles dizem respeito aos aspectos mais básicos da insegurança ontológica pois se referem a substância básica da interação de todos os dias, efetuada através do controle dos gestos corporais do rosto, do olhar e do uso da linguagem.

Os moradores de rua são perpassados e controlados por esses olhares. Em seus relatos há uma queixa em relação aos cidadãos da "cidade organizada”: sua aparência decadente é vista como repugnante; ao invés de respeitados são temidos como bandidos; simplesmente não existem, são eliminados em seus olhares, sempre desviados. Como diz a pesquisadora, "às vezes os "animais" (cachorros, geralmente) são o único 'calor humano' de que usufruem, nutrindo suas essências de humanidade".

Comprometer a segurança ontológica é comprometer a saúde mental, a noção de ser, de existir para o outro em sua completude. É o que se faz com o morador de rua. Como esquecer a operação de "limpeza étnica e social" ocorrida recentemente em Corumbá, quando pessoas foram transformadas em objeto, lixo a ser despejado em outro Estado?

Há ainda o problema da vergonha, que remete diretamente para a auto-identidade, porque é pública, exposta. E Neilton, afirmando: “....nem diga (à mãe) que eu tô sofrendo, ou que me viu, nem nada!”

E José: "Eu disse: eu estou viajando para fora...” e era mentira, estava em São Paulo mesmo (morando na rua).

A vergonha provoca sentimentos de desadequação ou humilhação. Ela se liga à confiança, podendo destruí-la ou ameaçá-la. Como se vê, viver na rua implica no desmoronar de todos os alicerces antológicos.

No entanto, o amor transformou quatro pessoas. O amor de D. Silvia; do japonês que doa o cobertor novo; de Cara Queimada que oferece seu cobertor a Fernanda; de Hélio; de Gino; Neilton; Magali. Os modelos saudáveis, a vida, se sobrepuseram à morte. Daí a força incrível dessas pessoas, sua capacidade de resiliência Suas identidades, massacradas, emergem; sua fome é de amor e reconhecimento.

A sociedade não é só filicida. Há pais, filhos e irmãos amorosos. Apesar do Grande Pai e do Grande Irmão.

Quando o empregador de Neilton diz que ele merecera o almoço ao quebrar um bloco de concreto, sua resposta é: "Eu não me chamo comida, senhor, eu me chamo trabalho e honestidade e quero saber quanto é que estou ganhando, quanto é que vou ganhar".

É a voz do humano que não se resume ao concreto, à comida. Sua fome é de algo maior, simbólica, especificamente humano: sua identidade, o respeito, o reconhecimento, o lugar na ordem simbólica e, fundamentalmente o afeto.

Deixemos as palavras finais com Hobsbawn (1995):

"Sabemos que por trás da opaca nuvem de nossa ignorância e da incerteza de resultados detalhados, as forças históricas que moldaram o século continuam a operar. Vivemos num mundo conquistado, desenraizada e transformado pelo titânico processo econômico e técno-científico do desenvolvimento do capitalismo que dominou os dois ou três últimos séculos. Sabemos, ou pelo menos é razoável supor que ele não pode prosseguir ad infinitum. O futuro não pode ser uma continuação do passado e há sinais, tanto externamente quanto internamente, de que chegamos a um ponto de crise histórica. As forças geradas pela economia técno-científica são agora suficientemente grandes para destruir o meio ambiente, ou seja, as fundações materiais da vida humana. As próprias estruturas das sociedades humanas, incluindo mesmo algumas das fundações sociais da economia capitalista estão na iminência de serem destruídas pela erosão que herdamos do passado humano. Nosso mundo corre o risco de explosão e implosão. Tem de mudar.

Não sabemos para onde estamos indo... Contudo, uma coisa é clara. Se a humanidade quer ter um futuro reconhecível, não pode ser pelo prolongamento do passado ou do presente. Se tentarmos construir o $3^{\circ}$ milénio nessa base, vamos fracassar. E o preço do fracasso, ou seja, as alternativas para uma mudança da sociedade é a escuridão.” 


\begin{abstract}
This article intends to establish a dialogue with the article "Resilience and homelessness: a study on homeless - adults and child - in the city of São Paulo" by means of reflections deriving from it. The article relates the themes of resilience and homelessness to the current neo-liberal model in Brazil and to the process of social exclusion resulting from it. Some conceptions of resilience are discussed so as to demonstrate that there is no consensus about the issue. The life of the homeless is analysed based on the interplay between the concepts of identity, ontological insecurity, existential non-confirmation and fixed point as a lever to resilience: love interactions as the basis for existence and affirmation of the self.
\end{abstract}

Key-words: social exclusion; love interaction; fixed point; identity.

\section{REFERÊNCIAS BIBLIOGRÁFICAS}

ALVAREZ, A. M. d. S. A resiliência e o morar na rua: estudo com moradores de rua - criança e adultos - na cidade de São Paulo. São Paulo, 1999. [Dissertação de Mestrado - Faculdade de Saúde Pública da USP].

ENRIQUEZ, E. Da horda ao Estado. Rio de Janeiro, Jorge Zahar Editor, 1990.

FORRESTER, V. O horror econômico. São Paulo. Editora da UNESP, 1997.
GIDDENS, A. Modernidade e identidade pessoal. Oeiras, Portugal, Celta Editora, 1997.

HOBSBAWN, E. Era dos extremos. São Paulo, Companhia das Letras, 1995.

KIERKEGAARD, S. Temor e terror. São Paulo, Livraria Exposição do Livro, 1964.

MILNER, M. O papel da ilusão na forrnação simbólica. In: KLEIN, M.; HEIMANN, P.; MONEY-KYRLE, R. E. (orgs.). Novas tendências na Psicanálise. Rio de Janeiro, Zahar Editores, 1969. 